\title{
CONDIÇÕES E MODOS DE PARTICIPAÇÃO DE UM ALUNO COM DEFICIÊNCIA MÚLTIPLA NO COTIDIANO ESCOLAR DO ENSINO FUNDAMENTAL
}

\author{
CONDITIONS AND MODES OF PARTICIPATION OF A STUDENT WITH MULTIPLE \\ DISABILITIES IN THE ELEMENTARY SCHOOL ROUTINE \\ CONDICIONES Y FORMAS DE PARTICIPACIÓN DE UN ALUMNO CON CAPACI- \\ DADES ESPECIALES EN EL COTIDIANO ESCOLAR DE LA EDUCACIÓN PRIMARIA
}

Flavia Faissal de Souza

Professora Adjunta da Faculdade de Educação da Baixada Fluminense/Universidade do Estado do Rio de Janeiro (FEBF/UERJ). faissalflavia@gmail.com

Débora Dainez Pós-doutorado, bolsista Fapesp, FE/Unicamp. ddainez@yahoo.com.br

\begin{abstract}
RESUMO: Tomando como base os princípios teórico-metodológicos da perspectiva histórico-cultural do desenvolvimento humano, em especial a gênese social e o caráter mediado das funções psicológicas, esse artigo tem como objetivo problematizar as condições, os modos de participação e as possibilidades de inserção de um aluno com deficiência múltipla nas práticas escolares de uma escola de ensino fundamental. Inserido em um projeto coletivo de pesquisa, cuja inspiração era o enfoque metodológico da etnografia e da análise microgenética, o trabalho de campo foi desenvolvido ao longo de 2 anos, junto a um aluno com deficiência múltipla. Para registro da pesquisa de campo foram utilizados diário de campo e videogravações. As nossas análises evidenciaram a precariedade das condições sociais e institucionais para sustentar a participação do aluno com deficiência múltipla nas práticas educacionais. Em contraponto, quando diante de situações que potencializaram a mediação pedagógica, se explicitaram possibilidades de participação desse aluno no contexto escolar, mesmo que distantes do esperado para um aluno de quinto ano. $\mathrm{O}$ argumento que asseguramos a partir dessas discussões é que as condições escolares incidem na produção das relações de ensino e se tornam condição de desenvolvimento humano. Portanto, em defesa da educação dos alunos com deficiência sob a responsabilidade do Estado, faz-se imprescindível rever as diretrizes políticas de Educação Básica e Especial tendo como suporte a forma como essas vêm se materializando no cotidiano das escolas brasileiras, a fim de viabilizar o pleno desenvolvimento humano da pessoa com deficiência.
\end{abstract} PALAVRAS-CHAVE: Educação Especial. Políticas de Educação Inclusiva. Práticas Escolares. Trabalho Pedagógico. Deficiência Múltipla.

ABSTRACT: Using theoretical and methodological principles of a historical-cultural perspective of human development, particularly, social genesis and the mediated character of psychological functions, this article analyzes the conditions, modes of participation and the possibilities of integration of a student with multiple disabilities in the educational practices of an elementary school. Inserted into a collective research project that had, as its inspiration, the methodology of ethnography and microgenetic analysis, this field work experience was developed during a period of two years with a student with multiple disabilities. To register the field experience we used a field journal and video recordings. Our analyses showed the precariousness of social and institutional conditions in sustaining participation of a student with multiple disabilities in educational practices. In contrast, when faced with situations where there was a greater effectiveness of pedagogical mediation, there were possibilities for the student to participate in the educational context, even if the student's performance was distant from what is expected of a fifth grader. The argument that we put forth from these discussions is that educational conditions affects the production of educational relationships and become a condition for human development. Therefore, in defense of education for students with multiple disabilities under the responsibility of the State, it is necessary to rethink the political guidelines of primary, secondary and special needs education, basing oneself on the way this has materialized in the day to day routine of Brazilian schools so that the full human development of people with multiple disabilities can be enabled.

KEYWORDS: Special education. Policies for inclusive education. Educational practices. Pedagogical work. Multiple deficiencie.

$\overline{\text { Artigo recebido em maio de } 2016}$

Aprovado em julho de 2016 
RESUMEN: Este artículo tiene como objetivo problematizar las condiciones, las formas de participación y las posibilidades de inserción de un alumno con capacidades especiales en las prácticas escolares de una escuela de Educación Primaria, sobre la base de los principios teórico-metodológicos de la perspectiva histórico-cultural del desarrollo humano, especialmente la génesis social y el carácter mediado por las funciones psicológicas. Situado dentro de un proyecto colectivo de investigación, cuya inspiración fue el enfoque metodológico de la etnografía y del análisis microgenético, el trabajo de campo fue desarrollado a lo largo de dos años junto a un alumno con capacidades especiales. Para registrar la investigación de campo, se utilizó un diario de campo y grabaciones de vídeo. Los análisis realizados evidenciaron la precariedad de las condiciones sociales e institucionales para mantener la participación del alumno con capacidades especiales en las prácticas educacionales. En cambio, frente a situaciones que potencializan la mediación pedagógica se percibieron posibilidades de participación de ese alumno en el contexto escolar, aunque lejos de lo esperado para un alumno de quinto grado. El argumento que se plantea a partir de esas discusiones es que las condiciones escolares inciden en la producción de las relaciones de la enseñanza y se tornan una condición del desarrollo humano. Por lo tanto, en defensa de la educación de los alumnos con capacidades especiales bajo la responsabilidad del gobierno, se hace imprescindible revisar las directrices políticas de la Educación Básica y Especial, basándose en la forma de cómo estas se materializan en el cotidiano de las escuelas brasileñas, con el objetivo de permitir el pleno desarrollo humano de personas con capacidades especiales.

PALABRAS CLAVE: Educación Especial. Políticas de Educación Inclusiva. Prácticas Escolares. Trabajo Pedagógico. Capacidades Especiales. 


\section{1 | INTRODUÇÃO}

A presença do aluno com deficiência na escola regular se concretiza na contemporaneidade sustentada pelos acordos internacionais (UNDP et al., 1990; UNESCO, 1994; UNITED NATIONS, 2007; BRASIL, 2009), que ao longo dos anos, por questões políticas e econômicas, foram sendo incorporados pelos sistemas legislativos nacionais, e que hoje, prescrevem a obrigatoriedade legal de implantação de sistemas educacionais inclusivos (SOUZA, 2013). Nesta direção, a política assumida pelo MEC (BRASIL, 2008), Educação Especial na Perspectiva da Educação Inclusiva, parte do princípio de que a escola deve criar condições para atender à diversidade e não deve selecionar os alunos, em função de suas diferenças individuais, por apresentaram dificuldades e limites no acompanhamento curricular, cuja causa pode ser orgânica ou não, alunos com diferentes possibilidades sensoriais e de comunicação, e alunos que apresentam altas habilidades/ superdotação. Prevê ainda a matrícula de todos os alunos, incluindo os com deficiência, na rede regular de ensino com o mínimo de distorção idade-série (BRASIL, 2004).

Muitos são os paradoxos dessa política educacional. Autores como Laplane $(2014,2015)$, Caiado e Laplane (2009), Garcia (2009), Kassar (2011a, 2011b, 2012), Souza (2013), Pletsch e Mendes (2014) apontam que a proposta política da educação inclusiva prevê um avanço no que diz respeito ao acesso à educação daqueles cidadãos que tem vivido à margem de seus direitos. Contudo, suas diretrizes entram em conflito no processo de implementação nas escolas públicas brasileiras. A efetivação dessas políticas frente às condições concretas das nossas escolas é um desafio que se recoloca constantemente nos estudos supracitados.

O binômio inclusão-exclusão, implícito na ideia da Educação Inclusiva, é problematizado por Daniels (2011), pelo ponto de vista da Sociologia, da Psicologia e da Educação, ao analisar a situação da exclusão ao acesso e permanência com qualidade à instituição escolar como precursor possível de uma condição de vida marcada por processos de exclusão de direitos. O autor defende a ideia de "exclusão profunda", uma forma de exclusão mais alargada, que corresponde à posição de desvantagem em mais de uma dimensão social. Essa exclusão resulta em graves consequências negativas que impedem a ampliação das possibilidades futuras de participação social dos sujeitos. Essa forma de "exclusão profunda" torna-se permanente no (e pelo modo de organização do) sistema de ensino, desencadeando uma trajetória de dificuldades, fazendo com que o aluno com deficiência acabe por retornar à escola especial assistencialista ou que permaneça na escola comum sem contar com condições institucionais efetivas para sua plena inserção nas práticas educacionais.

Nesta linha, estudos como os de Caiado (2013) e Laplane (2014), também apontam que embora se tenha garantido o acesso físico à escola, a acessibilidade ao conhecimento ainda se apresenta como desafio na contemporaneidade.

Em meio a esses desafios da política educacional, participamos no decorrer de três anos letivos de uma pesquisa no cotidiano de uma escola pública municipal de periferia da cidade de Campinas, SP, que se insere em um projeto coletivo que teve como propósito a investigação das condições de desenvolvimento humano e as relações de ensino nas práticas contemporâneas. No entrelaçamento das análises dos estudos uma questão em especial nos chamou atenção: o impacto das condições de ensino nos modos de participação de um aluno com deficiência múltipla nas práticas cotidianas escolares. Desta forma, o objetivo deste trabalho é discutir as condições de ensino e os modos de participação de um aluno com deficiência múltipla nas práticas educacionais. 
Para essa discussão, os pressupostos que assumimos referem-se à natureza social do desenvolvimento humano da perspectiva de Vygotski' $(1995,1996,1997)$ e Vigotski (2000). Nesse modo de abordar, o nascimento biológico não é suficiente para declarar a existência do ser humano. A condição humana carece de outro nascimento, um nascimento social e semiótico, em que a linguagem (signo por excelência) e os demais instrumentos técnicos e semióticos, produzidos e estabilizados na história de relações, participam como fio mediador, condutor e constitutivo da criação de novas atividades e formações psíquicas (PINO, 2000; SMOLKA, 2004). Assim, conceber a sociogênese do desenvolvimento humano significa considerar a dimensão orgânica impregnada pela cultura e marcada pela história, (trans) formando um complexo sistema, uma dinâmica interrelação genética-estrutural-funcional da atividade psicológica.

Desta forma, Vygotski (1997) se interessa em compreender como o ser humano nasce na e da cultura e, ainda, como esse processo ocorre nas condições de desenvolvimento marcadas pela deficiência. É justamente na discussão sobre a condição de lesão orgânica que o autor ressalta e tonifica os princípios do desenvolvimento cultural, processo que corresponde ao desenvolvimento psíquico que se produz entrelaçado ao desenvolvimento histórico da sociedade. Neste sentido, o autor afirma que é o meio social e não a natureza orgânica que deve figurar como fator determinante do comportamento do homem. É através do processo de apropriação das relações e práticas sociais pela significação, trabalho com signos e sentidos, que temos a possibilidade de (trans) formação das funções psicológicas e de suas interrelações, ampliando as possibilidades de desenvolvimento.

Diante disso, estudos como o de Bottcher (2012), por exemplo, mostram como pelo ponto de vista da abordagem histórico-cultural, é possível deslocar o modelo médico de deficiência - que toma como ponto de partida a relação direta entre o defeito biológico e a impossibilidade de desenvolvimento, e destacar os processos educativos que se tornam condição de constituição do indivíduo. Segundo a autora, as práticas sociais e educacionais sustentam as atividades psicológicas, de modo a criar possibilidades ou constrangimentos que alimentam o aprendizado da criança.

De toda a forma, indivíduos com deficiência estão envoltos no entrelaçado desenvolvimento cultural, estão se constituindo na contradição das relações sociais. Isso se evidencia no percurso de reformulação do conceito de compensação na obra de Vigotski a partir de uma perspectiva histórico e culturalmente orientada (DAINEZ, 2014). As formas sociais impeditivas de participação nas práticas de ensino e aprendizagem, de apropriação do conhecimento também são constitutivas do desenvolvimento.

Portanto, assumindo que o desenvolvimento humano tem uma base orgânica que é impregnada da dimensão histórico-cultural e que a deficiência coloca em perspectiva a formação social e semiótica das funções psicológicas, problematizamos as condições, os modos de participação e as possibilidades de inserção de um aluno com deficiência múltipla no cotidiano escolar de uma escola de ensino fundamental.

\footnotetext{
${ }^{1}$ No decorrer do texto, a grafia utilizada no nome de L. S. Vigotski será como aparece nas referências utilizadas, para facilitar a busca bibliográfica. As diferentes formas de grafia se dão pelas distintas traduções do nome do autor, originalmente grafado em russo.
} 


\section{2 | DESENVOLVIMENTO}

\subsection{Procedimentos Metodológicos}

Conforme já dito, a presente pesquisa elegeu uma escola de Ensino Fundamental como lugar de realização do trabalho empírico. Acompanhamos, durante dois anos, um aluno com deficiência múltipla ${ }^{2}$, Alan $^{3}$. Em ambos os anos em que foi acompanhado, por ter sido reprovado, o aluno encontrava-se matriculado e frenquentando uma turma do $5^{\circ}$. ano do Ensino Fundamental. As situações vividas e compartilhadas na instituição escolar são tomadas como objeto de análise pelo que evidenciam das condições/relações de ensino e desenvolvimento. Como procedimentos de registros das situações vividas utilizamos o caderno de campo e a vídeogravação.

Deste modo, o desenho teórico-metodológico para registro e análise de situações cotidianas teve como inspiração o enfoque etnográfico que permite a imersão/participação do pesquisador no cotidiano escolar, de modo a vivenciar os seus conflitos e compreender suas contradições (EZPELETA; ROCKWELL, 1989). Também trabalhamos com a análise microgenética (GÓES 2000; WERTSCH; HICKMANN, 1987), inscrita numa interpretação histórico-cultural dos processos psicológicos, permitindo o estudo da emergência de novos modos de atividade do indivíduo em desenvolvimento. Essa forma de análise implica orientar a atenção para o curso de desenvolvimento, eleger episódios que permitam interpretar o fenômeno de interesse e investigar a constituição de indivíduos no âmbito das práticas e das relações sociais. Em outras palavras, atende os princípios de que a gênese das funções psicológicas está nas relações sociais e de que a constituição do funcionamento humano é socialmente mediada.

Deste modo, ao adotar essas premissas, o nosso trabalho de investigação e teorização foi feito na dinâmica das relações, nas constantes retomadas e ponderações. Em outras palavras, foi à realização da pesquisa "por um fio", num desdobrar-se contínuo de questões e elaborações que vão emergindo no dia-a-dia da nossa participação na escola (SMOLKA, 2012).

\subsection{Possibilidades analíticas: condições e os modos de participação do aluno com defi- ciência múltipla no ensino fundamental}

Antes de determo-nos ao material empírico, faz-se importante retomarmos algumas características que nos ajudam a descrever as condições do aluno com deficiência múltipla, Alan.

À época do primeiro ano do estudo, Alan estava com 10 anos, não falava e realizava poucos movimentos voluntários de membros superiores e inferiores. Embora estivesse inserido em serviços públicos de saúde, desde o seu primeiro ano de vida, não teve acesso à Comunicação Aumentativa e Alternativa (CAA) sistematizada. Era usuário de uma cadeira de rodas, com um quadro de tetraplegia, sem autonomia para realizar atividade alguma; fazia uso de dosagens altas de medicamentos para tratamento de episódios convulsivos. Em sua cadeira, o aluno levava todos os dias para a escola uma sacola com brinquedos para estimulação sonora e realização de massagens. Alan freqüentava a mesma escola já havia quatro anos. No primeiro ano do estudo, o

\footnotetext{
${ }^{2}$ Deficiência múltipla decorrente de Síndrome de Angelman. Segundo o CID - 10 (Classificação Internacional de Doenças) (WHO, [200-]), esta síndorme está inserida no capítulo que diz respeito às malformações congênitas, deformidades e anomalias cromossômicas.
}

${ }^{3}$ Os nomes utilizados são pseudônimos. 
aluno foi retido no 50 ano, pois a equipe pedagógica da escola tinha receio de como seria a inserção dele na segunda etapa do Ensino Fundamental. Contudo, devido às normas da rede de ensino na qual estava matriculado, dois anos depois, Alan foi promovido ao 60 ano, mesmo que ainda apresentando características e condições de desenvolvimento muito próximas as dos anos anteriores. Em outras palavras, a promoção aconteceu pelo critério idade-série 4 .

Em nenhum dos anos da pesquisa, o aluno esteve matriculado, nem frequentou o serviço de Atendimento Educacional Especializado (AEE). Embora, existisse em sua escola uma sala de Recursos Multifuncionais, conforme parceria e diretrizes do Ministério da Educação (MEC). A sala de Recursos Multifuncionais, de acordo com as diretrizes locais, deveria atender alunos com deficiência visual e auditiva.

Para efeitos desse estudo, apresentaremos a descrição das turmas, as condições escolares e as cenas cotidianas registradas, organizadas nos anos letivos pesquisados.

\section{Primeiro ano da pesquisa}

A turma de 50 ano na qual Alan encontrava-se matriculado e frequentando era composta por 38(trinta e oito) alunos, sendo três com deficiências: um com deficiência intelectual, um com deficiência auditiva e o próprio com deficiência múltipla. Elen, a professora, não contava com assistente pedagógico em sala. Dos 35 (trinta e cinco) alunos sem deficiências diagnosticadas, haviam 02 (dois) não alfabetizados e um grupo de outros 07 (sete) alunos com grande defasagem de conhecimento sistematizado em relação ao conteúdo programado para o 50 ano ${ }^{5}$. Devido à grande heterogeneidade de sua turma, a professora normalmente trabalhava em grupos, com propostas pedagógicas diferenciadas. Sempre trabalhava conteúdos que fossem importantes no cotidiano da vida dos alunos, lançando mão de músicas, dramatizações e material de apoio pedagógico para as atividades propostas. Embora, Elen nunca tivesse participado de formação específica, no decorrer de sua vida docente teve a oportunidade de trabalhar com diversos alunos com deficiências.

Os alunos da classe se voluntariavam para auxiliar nos cuidados junto ao Alan. Em alguns momentos, vivenciamos situações nas quais foi possível perceber que alguns alunos o tratavam com carinho. Mas, também, frente a sua condição de extrema dependência, notamos, inúmeras vezes, a expressão de sentimento de pena por parte de seus pares.

Embora, neste cenário, possamos vislumbrar a construção de um olhar mais solidário frente à diversidade, a professora, não raramente, queixava-se da intensificação do seu trabalho enquanto docente e de seu desconforto em não conseguir realizar todas as tarefas que para ela deveriam ser cumpridas. Ao longo do ano, pudemos vivenciar diferentes formas de participação e de estabelecimento de relação entre Alan, Elen e os outros alunos da turma. Trazemos para esse estudo, 3 (três) cenas, que ilustram alguns dos momentos vividos.

\footnotetext{
${ }^{4}$ Dados coletadas a partir dos documentos arquivados nas pastas do aluno na secretaria da escola e no setor de Educação Especial.

${ }^{5}$ Com a implementação dos Ciclos de Escolarização na rede de ensino, em 2005, adotou-se a Avaliação Diagnóstica e da Descrição de Saberes. Essa proposta de avaliação é baseada na análise do que cada aluno sabe em relação ao coletivo da turma, na busca de "aprendizagens consolidadas e o que falta aprender", para posterior agrupamento dos alunos por níveis de saberes já consolidados e, por fim, a partir desses grupamentos por saberes e das necessidades de aprendizagem observadas - inclusive as referentes aos alunos com deficiências - os professores devem traçar os "objetivos para toda a turma e para cada grupo, visando ao planejamento de aulas com atividades que contribuam para que todos os alunos avancem na construção de conhecimentos. Deve ainda contar com avaliação constante, recuperação contínua e paralela, autoavaliação, entre outros (SÃO PAULO, 2011, p. 63-65).
} 
Cena 1:

Elen está corrigindo problemas matemáticos, ri para Alan, vai sentando, pega o microfone e diz:

1. (00:27:52) - Elen: E aí meu amor! Quer que faça massagem, lindo! Vem vamos fazer massagem [Pegando o pé de Alan].

Elen inicia a massagem nos pés de Alan, enquanto corrige os cadernos dos outros alunos em sua mesa.

(Registro Videogravação, 24.03.2009)

Cena 2:

A professora havia proposto como atividade, a dramatização da peça teatral 'Os três Porquinhos', texto que estava sendo trabalhado nas aulas de português. $O$ ensaio acontecia com a participação dos alunos ora como atores, ora como espectadores, ora como auxiliares técnicos. Elen os ensinava as várias possibilidades de se interpretar um texto.

Nesse período, Alan ria, acompanhava o ensaio e seguia Elen com os olhos, até que ela se aproximou dele. Nesse movimento de interação com a professora, Alan deu uma gargalha. Passado um tempo, Elen, que vocalizava os sons da sonoplastia da peça, se aproximou novamente de Alan, colocando o microfone em sua boca, dizendo: "Oi! Oi!" Dessa vez, Alan olhou fixamente para o microfone e riu.

Os dois continuaram interagindo. A turma continuava com os ensaios. Elen, para ensinar os alunos que representavam os três porquinhos a dramatizarem a caminhada para a floresta, entrou na peça conduzindo Alan em sua cadeira, dançando e cantando:

1. (00:09:05) - Elen: Quem tem medo do lobo mau, lobo mau... Chamando os alunos disse: Quem vai pelo caminho da floresta vem atrás de mim! [Pedindo que eles seguissem-na e a Alan.] O grupo continuou cantando e dançando. Alan seguiu atento.

(Registro Videogravação, 07.04.2009)

Cena 3:

Elen estava trabalhando com os alunos o conceito de medo que se desdobra para o de marginalidade, a partir da discussão do livro Chapeuzinho Amarelo, quando colocou em questão temas como leis, normas, padrões e o sistema de justiça.

1. (00:28:59) Elen: Então alguma coisa na sociedade está errada e nós temos que enfrentar isso. Esse vai preso, mas esse não vai preso. [pausa] Aí você vê escândalos, em cima de escândalos e não acontece absolutamente nada! Vira como eles dizem tudo pizza, acaba em pizza. [Se aproximando de Alan] Não é meu amor, [pausa] acaba tudo em pizza, né? [arrumando Alan na cadeira e olhando para ele] E você não tem uma escola que te dê um ambiente para você poder estar deitadinho, fazendo exercício [neste momento Elen vai fazendo movimentos com os membros superiores], fazendo atividades, né, meu amor? [Fazendo carinho no rosto dele e olhando em sues olhos]Você tem que ficar paradão, aqui com a Tia Elen [puxando a cadeira para junto a ela.]

2. (00:31:00) Neste momento uma aluna se lembra:_ Uma vez quase que eu e a Luane fizemos ele desenhar. A gente pego na mão dele botamos lápis, botamos papel e fizemos assim [fazendo gesto de rabiscar].

[...]

3. (01:07:43) A aluna retoma o assunto:_ A professora botava as duas mãozinhas dele assim [não dá para ver o gesto], e ele ficava. Quando tinha a mesa dele, ele ficava [referindo-se à mesa acoplada à cadeira do aluno].

(Registro Videogravação, 16.09.2009) 
Três cenas, três situações cotidianas de sala de aula, que ilustram as condições escolares para inserção do aluno com deficiência múltipla em uma turma de 50 ano do Ensino Fundamental e os modos de participação do mesmo. De diferentes formas, percebermos o esforço da professora em dar atenção e integrar Alan nas atividades pedagógicas desenvolvidas.

$\mathrm{Na}$ cena 1, a professora faz massagem em Alan. Apoiada em relatórios da área médica e nos relatórios pedagógicos existentes desde a entrada da criança na escola, sempre que possível, a professora desenvolvia, junto ao aluno, atividades de estímulo sonoro, vocalização de fonemas e massagens. Como os alunos com deficiência não participavam de processos de avaliação escolar, nos anos de permanência de Alan na escola, essas atividades sensoriais foram se estabilizando como práticas pedagógicas.

Ainda, vale destacar que segundo a professora Elen, a equipe pedagógica da escola não tinha formação adequada para trabalhar com Alan, desconhecendo as estratégias que pudessem dar suporte para inserção do aluno nos processos de ensino-aprendizagem.

Já na cena 2, Elen insere Alan na dinâmica, ao conduzi-lo para o ensaio da peça teatral. Participações de Alan, como a aqui relatada foram escassas. Alan dormia grande parte das $4 \mathrm{hs}$ diárias em que se encontrava na escola. Contudo, vale destacar que Elen se cobrava e insistia em desenvolver as atividades junto a Alan, pois acreditava que o aluno tinha sua estrutura cognitiva preservada e que compreendia tudo o que se passava à sua volta.

Na cena 3, Elen verbaliza, na frente de toda turma e da pesquisadora, as condições precárias para inserção deste aluno no ensino regular, que demandava cuidados e atenção específicos. Embora houvesse os equipamentos de Tecnologia Assistiva na Sala de Recursos Multifuncionais na escola, Alan não tinha acesso ao serviço. Não havia nenhum tipo de profissional auxiliar para acompanhar Alan.

A lembrança da aluna na cena 3, turno 2 e 3, nos remete a uma importante questão: em 2007, com a verba da conta da escola, foi comprada para uso do aluno uma cadeira que em sua estrutura permitia o encaixe de uma mesa. Entretanto, em fevereiro de 2009, como a cadeira estava pequena para Alan, ela foi devolvida pela família à escola. Alan havia recebido uma cadeira nova de um serviço de saúde, adequada a seu tamanho, mas sem uma mesa para ser acoplada, necessitando que outra fosse providenciada.

A partir das cenas aqui trazidas, ressaltamos a tensão entre as condições de vida do aluno e as da escola. Essas tensões nos levam à indagação: se o objetivo último das políticas de educação inclusiva é a participação efetiva do aluno nas práticas cotidianas escolares e a inserção nos processos de ensino e aprendizagem, qual o argumento que sustenta a matrícula de Alan em uma turma de 50 ano que não a distorção idade-série?

\section{$\underline{\text { Segundo ano da pesquisa }}$}

Essa turma era composta por 28 (vinte e oito) alunos, contando com Alan e duas alunas com dificuldades de aprendizagem. A professora, Beatriz, tinha experiência como recreacionista, cursou magistério e, no ano de 2010, estava concluindo o curso de Pedagogia. Trabalhou em escolas do Ensino Fundamental durante cinco anos e começou a lecionar nessa escola no ano de 2010. Durante o curso de Pedagogia, a professora conta que não teve disciplina específica sobre a questão da deficiência e, também, durante o seu tempo de atuação em escolas do ensino fundamental não recebeu cursos de capacitação específica para trabalhar com alunos com deficiências. Em relação a sua experiência profissional, antes de Alan, trabalhou com uma aluna com síndrome de Down e dois alunos com deficiência física, que estavam alfabetizados. A relação da 
professora com a turma é marcada pelo modo tranquilo de se dirigir aos alunos e pela preocupação em possibilitar debates e discussões coletivas sobre o tema em pauta para o estudo, dando voz aos alunos. Privilegiava trabalhos por meio de teatros, leituras e reconstrução coletiva de histórias.

A seguir, apresentamos e analisamos cenas registradas no cotidiano escolar.

\section{Cena 1}

Primeiro dia em que a pesquisadora entra na sala de aula do $5^{\circ}$. Ano/2010, a professora a recebe dizendo:

"Alan está sendo uma descoberta para mim. Não sei bem ao certo o que fazer com ele, porque não sei se ele compreende ou não, como ele realmente é, sabe? (...). Eu o deixo lá no cantinho da minha mesa, porque eu preciso cuidar dele. (...).Tem que ficar de olho nele porque ele afoga. (...). O que passaram pra mim é cuidar, fazer massagens e trocas sensitivas. Como ele não interage e não se comunica, então ele fica com o chocalho que faz som. (...). Ele não dá trabalho, se eu deixar ele fica a aula inteira dormindo. Muitas vezes ele tem um olhar perdido que é difícil imaginar no que ele está pensando. Mas é interessante que quando fala o nome dele ele já olha".

(Registro Diário de Campo, 29.03.2010)

\section{Cena 2}

A professora retorna de uma licença de 15 dias, por motivos de problemas de saúde. Numa conversa com a pesquisadora, ela diz "Deixa eu te contar uma coisa. Essa semana, no dia em que eu voltei, o Alan estava muito feliz. Nossa ele olhava para mim e ria sem parar, chegava até a dar gargalhadas. Ele não dormiu em nenhum momento. Ficou a aula toda se movimentando, mexendo com os braços, tocando o pandeiro, dando uns gritos, pra chamar minha atenção, daí eu olhava e falava com ele e daí ele ria e não tirava os olhos de mim. Eu não sei, mas eu fiquei achando que ele ficou contente porque eu voltei. Era o momento dele se expressar, de mostrar pra mim que sentiu minha falta". Um aluno que estava do lado comentou "É verdade o Alan estava morrendo de saudades da pro. Daí ele só dava risada sem parar porque ele estava feliz porque a pro voltou".

(Registro Diário de Campo, 30.04.2010)

\section{Cena 3}

A proposta de atividade era: Desenho com dobraduras de papéis coloridos sobre o tema (Folclore) do texto trabalhado para exposição na festa de inauguração da biblioteca da escola.

Os alunos desenham e fazem a dobradura. A professora coloca Alan sentado em dupla com um colega. Ela solicita que esse aluno fizesse a atividade na carteira de Alan para que este pudesse ver, considerando a dificuldade de sustentação de tronco. O aluno faz o desenho no campo visual de Alan. Em alguns momentos Alan orienta o olhar para o desenho do colega. Em outros, vira a cabeça em direção à professora que atendia outros grupos. A professora se aproxima e conduz Alan em sua cadeira de rodas pela a sala de aula. Passam pelas carteiras, param e a professora pede para que os alunos mostrem os trabalhos para Alan.

1. Professora: Olha Alan esse desenho (aponta para o desenho de um aluno).

2. Aluno: Mostra o desenho para Alan e diz "Curupira".

3. Alan: Olha para o desenho.

4. Professora: "Vamos ver outro". Empurra a cadeira de rodas de Alan e diz "gente mostra para o Alan os desenhos".

5. Alan: Olha para o seu lado esquerdo em direção a alguns colegas.

6. Aluno (que estava no lado direito de Alan): "Alan (prolonga a entonação da última sílaba). Levanta a folha com o desenho para Alan olhar". 
7. Alan: Vira o pescoço para o lado direito, em direção ao colega que o chamava.

8. Professora: Continua andando com Alan "Olha agora esse aqui Alan. É um coelho. Tá vendo aí o coelho?" (aponta em direção ao papel com o desenho que uma aluna levanta para mostrar).

9. Alan: Olha em direção ao desenho.

10. Vários alunos se levantam e vem até a professora e Alan, e começam a mostrar os desenhos.

11. Alan: Olha para os desenhos, mudando a direção da cabeça, ora para um lado (quando o desenho é mostrado no lado direito), ora para o outro lado (quando o desenho é mostrado no lado esquerdo), ora para frente (quando o desenho é mostrado nessa direção). $O$ tronco permanece sustentado, com a cabeça erguida e Alan olha para todos os lados da sala de aula.

(Registro Vídeogravação, 20.08.2010)

A partir dessas cenas, continuamos orientando esforços em dar visibilidade às condições escolares e aos diferentes modos de participação do aluno com deficiência múltipla na configuração de outras relações e práticas educacionais.

Assim como nos mostra as análises em relação ao primeiro ano de acompanhamento desse aluno, novamente deparamos com condições escolares insuficientes para atender Alan. A única mudança é que a sua cadeira de rodas passa a ter o suporte mobiliário adequado com uma mesa acoplada.

$\mathrm{Na}$ primeira cena, observamos as tentativas iniciais de aproximação da professora Beatriz com o aluno com deficiência múltipla que são afetadas e orientadas pela história de relações, de signos e significados sociais de Alan na escola - o modo de conceber esse aluno (não comunica, não responde, não compreende, não interage); as práticas que foram possíveis de serem realizadas e que se tornaram estabilizadas no trabalho com esse aluno, com foco no cuidado (deixá-lo dormir devido aos usos que fazia de medicamentos anticonvulsivos, dar água, não deixá-lo afogar, limpar a baba), no trabalho de estimulação (com os objetos do próprio aluno, fraldas, brinquedos com som - chocalho, copo de plástico). Os comportamentos e as respostas desse aluno a essas condições são: dorme o maior tempo da aula, balança um chocalho que produz som, mantém uma atenção dispersa, acompanha com os olhos o movimento dos objetos quando é estimulado sensitivamente. O lugar físico ocupado pelo aluno é ao lado da mesa da professora.

Entretanto, no discurso da professora Beatriz, notamos que ela não tem certezas sobre o trabalho que vem realizando com o aluno e não tem certezas sobre as capacidades dele. Ao mesmo tempo em que afirma "ele não interage, ele não fala", ela atenta para o olhar de Alan, que pode ser uma via possível de dizer do aluno ("quando fala o nome dele ele já olha"; "Muitas vezes ele tem um olhar perdido que é difícil imaginar no que ele está pensando") e de interpretação e compreensão do outro.

A incerteza quanto às (im)possibilidades do aluno e a dúvida do trabalho realizado com ele se intensifica no cotidiano das relações produzidas. A professora, então, ao mesmo tempo em que estimula, cuida, orienta ações para um trabalho de interpretação dos movimentos e das expressões do aluno, atribuindo significado e nomeando as suas ações (sorriso de felicidade, de saudades), conforme podemos observar na cena 2. Na dinâmica das interrelações sociais, significados sobre as possibilidades (de resposta, de significação, por exemplo) desse aluno vão sendo construídos e sustentando novos modos de participação de Alan nas interações.

Na cena 3 deparamos com tentativas deliberadas de intermediação da professora com o propósito de inserir, de alguma forma, o aluno com deficiência na atividade proposta para a classe, ou mais, de envolvê-lo no processo de significação e colocá-lo numa rede de relações com os outros. 
Chamamos a atenção para o lugar físico ocupado por Alan nessa situação. A professora coloca Alan sentado em dupla com um colega e solicita que esse faça a atividade em cima da mesa de Alan. Vemos a orientação do olhar de Alan para a atividade que o aluno realizava e para a professora que conversava e auxiliava outros alunos. Embora o colega faça a atividade em cima da mesa de Alan, conforme a solicitação da professora, ele não conversava ou tentava interagir com Alan. A professora Beatriz, ao notar que Alan estava olhando para ela, se aproxima do aluno e o leva a andar pela sala para ver as produções dos colegas. Os alunos mostram e nomeiam os desenhos para ele (linha 2). A professora também nomeia, aponta (linha 8). Gestos que se orientam de forma a conduzir a atenção de Alan e a sustentar o direcionamento de seu olhar. Alan responde olhando em determinada direção em que o desenho é apresentado. A sua resposta, por sua vez, sustenta a ação direcionada dos outros em relação a ele. Muitos alunos começam a se deslocar de suas carteiras até o lugar onde a professora se encontrava com Alan, e apresentam as suas produções.

\subsection{Discussões}

Primeiramente, consideramos importante listar algumas das condições para permanência do aluno na escola em ambos os anos: o critério para enturmação de Alan era a relação idade-série; havia significativas diferenças entre as possibilidades de participação e de aprendizagem de Alan frente às práticas pedagógicas e o conteúdo curricular trabalhado nas aulas; o não investimento no processo de inserção do aluno em sistemas de Comunicação Aumentativa e Alternativa (CAA); a escola não dispunha em sua equipe de um cuidador; o não acesso do aluno aos equipamentos de Tecnologia Assistiva para dar suporte ao aluno; não havia outro mobiliário que permitisse retirar o aluno da cadeira, por isso ele permanecia as $4 \mathrm{~h}$ sentado na mesma posição, sem mudança de decúbito, o que desencadeou um problema na região do quadril, gerando a necessidade de realização de uma cirurgia no ano de 2011.

Salientamos que o não investimento em sistemas de CAA no decorrer da vida desse aluno, assim como o acesso precário aos demais serviços públicos tanto no âmbito da saúde como no da educação, é fator determinante no seu processo de aprendizagem e de desenvolvimento. Nesse escopo, a questão da linguagem é um ponto importante para pensarmos as condições de inserção de Alan no Ensino Fundamental. Alan não fala, mas escuta. E, ainda que falem com ele, o que de nosso ponto de vista é fundamental - posto que a palavra é a "unidade da linguagem e do pensamento" (VIGOTSKI, 2001, p. 18) e, quando dirigida ao outro, é ainda "uma espécie de ponte lançada entre mim e os outros" (VOLOCHINOV; BAKHTIN, 1995, p. 115) -, Alan, em razão de suas condições de desenvolvimento, não se constituiu com uma linguagem estruturada e organizada.

Essa questão se torna mais complexa quando assumimos que a função de enunciação, que é intrinsecamente articulada às formas de compreensão, é fundadora da constituição da linguagem humana (VIGOTSKI, 2001, p. 11), ainda mais quando adensada pela ideia de que a conduta verbalizada (expressiva) é um problema central de toda a história do desenvolvimento cultural da criança (VIGOTSKI, 2000).

No que tange à prática pedagógica, embora essas professoras encontrem na tarefa de ensinar, um contexto de precárias condições de implementação de uma política, estruturada em princípios ideais, que impactam negativamente as práticas pedagógicas (LAPLANE, 2004; GARCIA, 2004; KASSAR, 2011a, 2011b; SOUZA, 2013), evidenciamos a responsabilidade e o compromisso de ambas em acolher e tecer tentativas de trabalho com o aluno com deficiência na sala de aula. $O$ esforço para que o aluno com deficiência participe da vida social e acadêmica da turma é visível 
na prática de Elen e de Beatriz. Isso fica ressaltado no gesto realizado pelas duas professoras em locomover a cadeira de rodas na sala.

E mais, quando nos detemos a analisar as relações de ensino e os modos de participação de Alan, em ambos os anos, faz-se necessário, discutirmos os diferentes contextos e condições de aula. Na turma de 2010 havia dez alunos a menos em seu grupamento e somente um aluno com deficiência. A professora Beatriz estava no início de sua carreira profissional e iniciando o trabalho nessa escola. Já Elen estava em processo de aposentadoria e de adoecimento, devido as suas condições de trabalho.

Tanto a prática pedagógica de Elen quanto de Beatriz refletem as marcas das recomendações e intervenções da área da saúde. Contudo, vemos tentativas mais incisivas de reorientação do modo de atuação da professora Beatriz em relação ao aluno com deficiência. Notamos, a partir dos registros do cotidiano escolar, que a professora Beatriz, insiste em aproximar Alan das atividades pedagógicas propostas pela turma.

Desse modo, diferentes condições vão marcando distintas relações de ensino que repercutem/ sustentam no/o modo de participar de Alan na sala de aula. Nos estudos de Vygotski (1997) sobre a deficiência, o pressuposto da natureza social do desenvolvimento humano e da inter-relação das funções psicológicas, ajudam a problematizar as dinâmicas das interações sociais e o que vai se produzindo nelas, contribuindo para a compreensão da atividade mental do indivíduo sustentada pelo outro nas diferentes práticas sociais e institucionais.

Reiteramos, com isso, que as possibilidades de participação do aluno Alan são indissociáveis à participação do outro e às condições das relações de ensino. É por esse viés, que chamamos a atenção aos gestos produzidos nas relações de ensino, envolvendo esse aluno com deficiência múltipla: o gesto de fazer a massagem, o gesto de conduzir a cadeira, o gesto de reclamar por condições adequadas para inserção do aluno no ensino regular, o gesto do sorriso de Alan que é interpretado pela professora como felicidade pelo seu retorno, o gesto de mostrar a folha desenhada ao aluno e de nomear o desenho. Segundo Smolka (2010, p. 6), o gesto é "um movimento marcado/transformado por uma relação social, no qual se inscreve a significação"; são construções sociais, instituições que condensam e expressam uma história de relações e produções do homem sobre o outro e sobre si mesmo. Desta forma, os gestos pedagógicos, os gestos do próprio aluno Alan e dos demais colegas nos dão a conhecer sobre as (im)possibilidades que residem na esfera do trabalho pedagógico na adversidade das condições escolares.

Diante do exposto, podemos considerar que no movimento da professora para inseri-lo nas atividades desenvolvidas com o restante da turma, o ato de interpretar/significar os movimentos desse mesmo aluno, muda o lugar da ação, o aluno não só recebe, ele também expressa. Nesse processo, novas possibilidades de ação, interação e participação de Alan e do outro são viabilizadas nas práticas cotidianas da sala de aula.

\section{3| CONSIDERAÇÕES FINAIS}

Os momentos vivenciados no cotidiano e condensados nos gestos dos professores e nos gestos desse aluno com deficiência são significativos pelo que nos dão a conhecer sobre as possibilidades e também de impossibilidades criadas pelas (faltas de) condições concretas.

As análises aqui trazidas nos colocam pontos importantes para pensarmos sobre a função social da escola e/ou sentidos da escola: Alan nasceu com graves impedimentos orgânicos, e nos seus primeiros anos de vida teve acesso a serviços precários tanto no âmbito da saúde, como no 
da educação. Nos anos da pesquisa, consideramos que as condições para inserção do aluno em um 50 ano do ensino fundamental foram precárias e as ações insuficientes, sobretudo frente suas condições de participação nas atividades propostas. Alan necessitava de cuidados específicos, que não estão previstos no escopo da estrutura de uma escola de ensino fundamental, além disso, o aluno nem ao menos foi matriculado no serviço de Atendimento Educacional Especializado existente na escola, pela compreensão da equipe pedagógica de que o mesmo não dava conta de atender as demandas desse aluno. Alan nos coloca no limite entre o papel dos serviços no âmbito da educação e da saúde.

Vemos que quando Alan foi inserido na escola, no segundo ano da pesquisa, com uma condição minimamente diferenciada, vivenciamos novas formas de relação de ensino e de participação do aluno. Ou seja, embora, distante do pretendido para um aluno de 50 ano, Alan nos deu respostas às solicitações da docente que antes não fornecia. Em outras palavras: contraditoriamente, estar inserido na escola pode (ria) ter impactado seu desenvolvimento de forma a redimensionar os seus graves impedimentos funcionais?

O argumento que sustentamos a partir dessas discussões é que as condições escolares impactam nas possibilidades de produção das relações de ensino que se tornam condição de desenvolvimento humano. Portanto, em defesa da educação dos alunos com deficiência sob a responsabilidade do Estado, faz-se imprescindível rever as diretrizes políticas - Educação Básica e Especial - tendo como suporte a forma como essas vêm se materializando no cotidiano das escolas brasileiras, a fim de viabilizar o pleno desenvolvimento humano da pessoa com deficiência. 


\section{Referências}

BOTTCHER, L. Culture and the learning and cognitive development of children with severe disabilities: continuities and discontinuities with children without disabilities. Mind, Culture and Activity: an International Journal, v. 19, n. 2, p. 89-106, 2012.

BRASIL. Decreto n 6.949, de 25 de agosto de 2009. Promulga a Convenção Internacional sobre os direitos das pessoas com deficiência e seu protocolo facultativo, assinado em Nova York, em 30 de março de 2007. Diário Oficial da União. Brasília, DF, 26 ago. 2009.

BRASIL. Ministério da Educação. Secretaria de Educação Especial. Educação inclusiva: o município. Brasília, DF: MEC; SEESP, 2004. 27 p. v. 2.

Ministério da Educação. Secretaria de Educação Especial. Política nacional de educação especial na perspectiva da educação inclusiva. Brasília, DF: MEC; SEESP, 2008.

CAIADO, K. R. M. Trajetórias escolares de alunos com deficiência. São Carlos: EdUFSCar, 2013.

CAIADO, K. R. M.; LAPLANE, A. L. F. Tramas e redes na construção de uma política municipal de educação inclusiva. In: BAPTISTA, C. R.; JESUS, D. M. (Org.). Avanços em políticas de inclusão: o contexto da educação especial no Brasil e em outros países. Porto Alegre: Mediação; CDV; FACITEC, 2009.

DAINEZ, D. Constituição humana, deficiência e educação: problematizando o conceito de compensação na perspectiva histórico-cultural. 2014. Tese (Doutorado em Educação)- Universidade Estadual de Campinas, Campinas, 2014.

DANIELS, H. Exclusion from school and its consequences. Psychological Science and Education, n. 1, p. 3850, 2011.

EZPELETA, J.; ROCKWELL, E. Pesquisa participante. 2. ed. São Paulo: Cortez; Autores Associados, 1989. 92 p.

GARCIA, R. M. C. Discursos políticos sobre a inclusão: questões para as políticas públicas de educação especial no Brasil. In: REUNIÃO DA ANPED, 27., 2004, Caxambu-MG. Anais... Caxambu-MG: ANPEd, 2004.

Política e gestão de educação especial nos anos 2000: a lógica gerencial. In: SIMPÓSIO BRASILEIRO DE POLÍTICA E ADMINISTRAÇÃO DA EDUCAÇÃO, 24.; CONGRESSO INTERAMERICANO DE POLÍTICA E ADMINISTRAÇÃO, 3., 2009, Vitória. Anais... Vitória: ANPAE, 2009.
GÓES, M. C. R. de. A abordagem microgenética na matriz histórico-cultural: uma perspectiva para o estudo da constituição da subjetividade. Cadernos CEDES, ano 20, n. 50, p. 09-25, 2000.

KASSAR, M. Educação especial na perspectiva da educação inclusiva: desafios da implantação de uma política nacional. Educar em Revista, Curitiba, n. 41, p. 61-79, jul./set. 2011a.

Educação especial na perspectiva da educação inclusiva: desafios da implantação de uma política nacional. Educar em Revista, Curitiba, n. 41, p. 61-79, jul./set. 2011b .

Educação especial no Brasil: desigualdades e desafios no reconhecimento da diversidade. Educação e Sociedade, Campinas, v. 33, n. 120, p. 833-849, jul./ set. 2012.

LAPLANE, A. L. F. Condições para o ingresso e permanência de alunos com deficiência na escola. Cadernos CEDES, v. 34, p. 191-205, maio/ago. 2014.

Notas para uma análise dos discursos sobre inclusão escolar. In: GÓES, M. C. R.; LAPLANE, A. L. F. (Org.). Políticas e práticas de educação inclusiva. Campinas: Autores Associados, 2004. 165 p.

O que os dados do censo escolar revelam sobre as barreiras à inclusão escolar? Educação e Fronteiras, Dourados/MS, v. 5, n. 13, p. 21-41, maio/ago. 2015.

PINO, A. O social e o cultural na obra de Vigotski. Educação \& Sociedade: Vigotsky - o manuscrito de 1929, Campinas: CEDES, ano 21, n. 71, p. 45-78, 2000.

PLETSCH, M. D.; MENDES, G. M. L. Dossiê educação especial: perspecitvas sobre políticas e processos de ensino-aprendizagem. Arquivos Analíticos de Políticas Educativas, v. 22, n. 77, p. 1-7, 2014.

SÃO PAULO. Prefeitura Municipal de Campinas. Secretaria Municipal de Educação. Departamento Pedagógico. Diretrizes curriculares da educação básica para o ensino fundamental e educação de jovens e adultos: um processo contínuo de reflexão e ação. Campinas: Millennium, 2011. $161 \mathrm{p}$.

SMOLKA, A. L. B. Condições de desenvolvimento humano e de realização do trabalho na escola: relações de ensino e coletivos de trabalho. 2012. Tese (Livre Docência em Educação)- Universidade Estadual de Campinas, Campinas, 2012. 
Ensinar e significar: as relações de ensino em questão ou das (não)coincidências nas relações de ensino. In: SMOLKA, A. L. B.; NOGUEIRA, A. L. H. (Org.). Questões de desenvolvimento humano práticas e sentidos. Campinas: Mercado de Letras, 2010. p. 107-128.

Sobre significação e sentido: uma contribuição à proposta de rede de significações. In: ROSSETTI-FERREIRA, M. C. et al. (Org.). Rede de significações e o estudo do desenvolvimento humano. Porto Alegre: Artes Medicas, 2004. p. 35-49.

SOUZA, F. F. de. Políticas de educação inclusiva: análise das condições de desenvolvimento dos alunos com deficiência na instituição escolar. 2013. 261 f. Tese (Doutorado em Educação) - Universidade Estadual de Campinas, Campinas, 2013.

UNDP et al. World declaration on education for all. In: Meeting basic learning needs: a vision for the 1990's. New York: UNICEF, 1990.

UNESCO. The Salamanca Statement and framework for action on special needs education. Paris: UNESCO, 1994.

UNITED NATIONS. Convention on the rights of people with disabilities and the optional protocol. New York: UN, 2007.
VIGOTSKI, L. S. A construção do pensamento e da linguagem. São Paulo: Martins Fontes, 2001. 496 p.

VIGOTSKI, L. S. Manuscrito de 1929. Educação \& Sociedade, Campinas: Cedes, ano 21, n. 71, p. 21- 44, 2000.

VOLOCHINOV, V. N.; BAKHTIN, M. M. Marxismo e filosofia da linguagem. 7. ed. São Paulo: HUCITEC, 1995. $196 \mathrm{p}$.

VYGOTSKI, L. S. Fundamentos de defectologia. In: Obras escogidas. Madrid: Visor Distribuiciones, S.A., 1997. v. 5.

VYGOTSKI, L. S. Problemas del desarrollo de la psique. In: Obras escogidas. Madrid: Visor Distribuiciones, S.A., 1995. v. 3.

VYGOTSKI, L. S. Psícologia infantil. In: . Obras escogidas. Madrid: Visor Distribuiciones, S.A., 1996. v. 4.

WERTSCH, J. V.; HICKMANN, M. Problem solving in social interaction: a microgenetic analysis. In: HICKMANN, M. (Org.). Social and functional approaches to language and thought. Nova York: Academic Press, 1987.

WHO. Internacional Classification of Disease (ICD) - 10. [200-]. Disponível em: <http://www.who.int/classifications/icd/en/>. Acesso em: 10 ago. 2013. 